
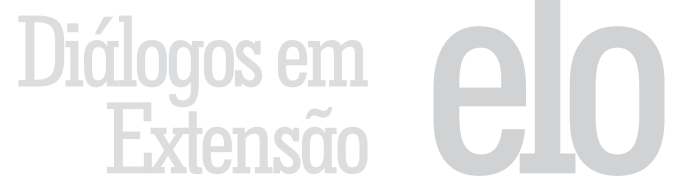

\title{
Espaço social (visões e revisões): experimentos de uma atividade interdisciplinar
}

Francisco Fagundes de Paiva Neto ${ }^{1}$, Francisco Fábio Dantas da Costa ${ }^{2}$

Resumo: $O$ trabalho partiu de um grupo de professores e pesquisadores de universidades da Paraíba, cujas reflexões no campo das Ciências Humanas demonstraram a possibilidade de discussões com egressos do ensino superior em uma extensão, por meio de um projeto. O objetivo foi analisar a noção de espaço desde o debate clássico ao contemporâneo, considerando a sua importância para se refletir sobre a sociedade, tanto em um nível macro como micro, que tem sido abordado pelas ciências humanas. Como metodologia, foi adotado um sistema de 12 módulos ministrados por profissionais de várias áreas, versando sobre temas envolvendo a perspectiva espacial. Um dos resultados da proposta foi a percepção, por parte dos envolvidos, de estabelecer relações críticas com as naturalizações feitas sobre o espaço, bem como de avaliá-lo como uma dimensão relacional entre representações e práticas sociais. Com efeito, percebeu-se que a atividade possibilitou um avanço no diálogo sobre a construção social dos espaços.

Palavras chave: Conflitos, espaço social, identidades sociais.

Áreas temáticas: Cultura e educação.

\section{Social space (visions and revisions): experiments on an interdisciplinaryactivity}

Abstract: This work was an initiative of a group of professors and researchers at universities of Paraiba state, northeast of Brazil, which reflections in the field of Human Sciences showed the possibilities of discussions with college students who took part of a project of extension. The objective was to analyze the notion of space from the classic debate to the contemporary, considering the importance to think about society in a macro and micro levels, according to the approaches in Human Sciences. As methodology we adopted a system of 12 modes given by professionals of several areas, about themes involving a spacial perspective. One of the results of the proposal was the perception from the involved ones, about establishing critical relations towards space, as well as

\footnotetext{
${ }^{1}$ Universidade Estadual da Paraiba, Prof. Dr. do Departamento de História. Contato: chicofagundes@ gmail.com.

${ }^{2}$ Universidade Estadual da Paraiba, Prof. Dr. do Departamento de Geografia. Contato: fabinhodantas1@ gmail.com.
} 
evaluating them in a relational dimension between representations and social practices. Therefore, it was observed that the activity facilitated the dialogue about building social spaces.

Keywords: Conflicts, social identities, social space.

\section{Espacio social (visiones y revisiones): experimentos de una actividad interdisciplinaria}

Resumen: El trabajo surgió de un grupo de profesores e investigadores interdisciplinarios e interuniversitarios de Paraíba, cuyas reflexiones en el campo de la Historia, Sociología y Geografía demostraron la capacidad de fomentarlas conversaciones con los graduados de la educación superior en un grado, a través de un proyecto de extensión. El objetivo fundamental fue analizar la noción de espacio desde el clásico hasta el debate contemporáneo, teniendo en cuenta la importancia de reflexionar sobre la sociedad, tanto a nivel macro y micro, que ha sido dirigida por las ciencias humanas de varios teóricos. Uno de los resultados de nuestra propuesta fue la percepción por parte de los involucrados en el proyecto, para establecer relaciones críticas con las nacionalizaciones realizadas por el espacio y para evaluarla como una dimensión relacional entre representaciones y practicas sociales. Para efectos concluyentes, nos dimos cuenta de que la actividad ha permitido un gran avance en el diálogo disciplinario sobre la construcción social de los espacios.

Palabras clave: Conflictos, espacio social, identidades sociais

\section{Introdução}

A presente proposta partiu de diálogos entre um grupo interdisciplinar e interinstitucional de professores e pesquisadores de universidades no estado da Paraíba, cujas reflexões no campo da História, Sociologia e Geografia demonstraram a possibilidade de fomentar discussões com profissionais egressos das Instituições de Ensino Superior oriundos das humanidades.

A temática do curso relacionou-se a um locus privilegiado para um debate científico interdisciplinar, porque versando sobre o espaço social, leva-nos às possibilidades de compartilhar e debater visões clássicas e contemporâneas sobre a noção em questão.

O conjunto de apreciações teóricas sobre o espaço, ao fim das atividades, possibilitou reflexões aprofundadas, tendo o caráter de uma formação suplementar aos cursistas envolvidos. Em termos quantitativos, concebemos como uma oportunidade de excelência no sentido de complementar as horas demandadas pelos currículos da nossa Instituição. 
O projeto em questão não contou com nenhum tipo de financiamento institucional, entretanto obtivemos uma bolsa para um estudante de graduação do Curso de Geografia (Cota UEPB/PROBEX 2012-2013).

\section{Aspectos teóricos e metodologias}

O Projeto de Extensão "Espaço Social: visões e revisões" ocorreu a partir da necessidade de realizar um enfoque plural das formas pelas quais os homens constituem e representam as sociedades, tanto nas suas relações em micro, como em macro escalas. O caráter desse empreendimento envolveu a colaboração de intelectuais de várias áreas do conhecimento, cujas perspectivas permitem uma visualização polifônica da noção em questão.

As leituras sobre o espaço partiram de diversos focos, possibilitando aos frequentadores da extensão reflexões sobre as contribuições dos historiadores, sociólogos e geógrafos. O projeto contou com apreciações em torno das visões sobre a relação entre o espaço e memória; a questão urbana na contemporaneidade; as identidades sociais em áreas rurais; os movimentos sociais e a constituição de territorialidades; as questões inerentes à geopolítica; as relações homem/natureza; representações sobre o desenvolvimento regional nos espaços rurais; as questões relacionadas às identidades nacionais e as visões internacionalistas; além, dos usos do ciberespaço na manutenção das identidades culturais dos povos pré-colombianos.

Esse conjunto de apreciações refletiu em uma formação suplementar aos cursistas, quando envolvidos nas produções dos variados modelos de trabalhos de conclusão de curso ou em projetos de pesquisa.

Consideramos que a metodologia de trabalho, a partir da discussão coletiva dos textos, da exibição de filmes e de documentários associados à atividade de campo possibilitou aos extensionistas uma compreensão do caráter multifacetado dos espaços socialmente construídos, demarcado por identidades sociais distintas, conflitos internos e externos, além de interações de diversos aspectos (BOURDIEU, 1996). O trabalho realizado pelos 12 professores participantes da atividade (sendo a coordenação dividida entre os professores Francisco Fagundes de Paiva Neto e Francisco Fábio Dantas da Costa) totalizou 180 horas/aula, tendo obtido aprovação da Pró-reitoria de Extensão/UEPB, sob o número de registro 2.37.035.12/13. O trabalho foi realizado em 10 (dez) meses, entre os anos de 2012 e de 2013.

O objetivo geral desse projeto foi analisar, a partir de visões interdisciplinares, as experiências sociais constitutivas do espaço social, cuja pluralidade exige a percepção dos momentos de instauração e de mudanças promovidas pelos indivíduos desde as suas interações e conflitividades 
demarcadoras de identidades sociais e de pertencimentos. Como objetivos específicos, citamos: analisar as relações entre os espaços sociais com as questões inerentes à memória e a questão simbólica; compreender o espaço urbano, enquanto produto da evolução do trabalho humano, como arena de produção e consumo e como somatório de tempos desiguais; avaliar as relações dos movimentos sociais com as questões de territorialização no campo; analisar a construção de diferentes identidades e espaços sociais rurais; refletir sobre os fundamentos teóricos, que compreendem o conceito de desenvolvimento associado às experiências rurais; compreender as relações engendradas entre poder, sociedade e espaço; discutir a historicidade da ideia de nação, que possui uma imbricada relação com as lutas por territórios; analisar os movimentos sociais, sob a perspectiva da resistência cotidiana; e, por fim, refletir acerca da sociedade informacional, percebendo o ciberespaço como um novo local de lutas para grupos marginalizados.

Assim, quanto aos referenciais teóricos, podemos contemplar relações voltadas às questões das identidades sociais e à formação de territórios políticos e nacionais, cujo apelo à memória e ao uso da história se torna um lugar de permanentes disputas e da constituição de distinções sociais entre os homens (BALANDIER, 1982; BOURDIEU, 1990, 1998; CASTELLS, 2006; POLLACK, 1989). A questão da mundialização dos espaços urbanos e rurais foi discutida como um fator de acentuação de conflitos sociais e de desenvolvimento desigual entre países e regiões do planeta em sintonia com a expansão dos impérios agroalimentares, da ampliação de áreas metropolitanas, do avanço industrial e dos monocultivos (CARLOS, 1996; CASTELLS, 2009; SANTOS, 1999).

Com efeito, a partir dessa bibliografia foram discutidos temas como pobreza, exclusão, democracia, cidadania, direito à cidade, reforma agrária, globalização, divisão internacional do trabalho, como forma de demonstrar os limites do desenvolvimento regional. Os movimentos sociais foram abordados a partir da formação do espaço agrário brasileiro, por meio de pesquisas que privilegiaram o uso de fontes orais, avaliando os problemas inerentes a expropriação da terra, as contradições entre os processos de conservação e dissolução de valores, práticas sociais e individuais em relação às novas condições de vida e trabalho em assentamentos (FELICIANO, 2006; FERNANDES, 2000; GOHN, 2007).

Quanto à dimensão nacional e geopolítica, foi realizada uma reflexão teórica sobre a geopolítica mundial, a partir da formação das nacionalidades modernas e tensões oriundas do nacionalismo e de movimentos de cunho internacionalista (COSTA, 2008; HOBSBAWM, 1990, 2008). Nesse processo foi utilizada a apresentação de mapas em contextos históricos diversos e um documentário sobre a Primeira e Segunda Guerra Mundial, além de reportagens sobre os conflitos atuais no Oriente Médio (BALAKRISHNAN, 2000). Através dos vídeos, foi feito um debate para 
compreender a influência que a geopolítica exerce nas guerras e nos conflitos internacionais, associando as recentes guerras movidas por recursos, como o petróleo.

A discussão específica sobre as condições de moradia e a questão urbana na história recente do Brasil partiu de um texto que destacava os instrumentos contidos na Lei 10.257/01 - Estatuto da Cidade e sobre a função social da propriedade nas áreas citadinas (RODRIGUES, 2003, 2004).

A relação das manifestações culturais com os episódios recentes da história nacional, a partir do golpe de 1964, foi analisada através da produção musical "brega" e os seus enleios políticos (ARAÚJO, 2005; NEZ, 2011). Neste caso, o objetivo foi discutir a construção dos espaços de poder, as territorialidades da política e suas dimensões históricas no contexto nacional e regional. As percepções do poder exercido por indivíduos e/ou grupos, as relações entre a política e as transformações geográficas e culturais da sociedade.

Por fim, diante da emergência do neopopulismo na América Latina e dos movimentos étnicos indígenas, foram analisadas as dimensões de resistência cotidiana e da noção thompsoniana de economia moral. Um estudo de caso sobre o movimento aymara boliviano e sua organização de sites no ciberespaço, visto como novo local de lutas já centenárias, demonstra as possibilidades de resistência política de povos pré-colombianos no século XXI, a exemplo dos próprios neozapatistas no México. Esta discussão objetivou ainda refletir acerca da sociedade informacional, percebendo o ciberespaço como um novo local de lutas para grupos marginalizados. Ademais, os estudos de Thompson (1998), de Scott (2000) e de Castro Neves (1998) serviram de suporte teórico para as discussões propostas.

As atividades como expressão de um trabalho coletivo ocorreram em salas de aula e auditórios, considerando os espaços físicos da Universidade Estadual da Paraíba e da Câmara Municipal de Guarabira/PB. Tivemos a frequência de uma média de 60 alunos ao longo do ano. Utilizamos materiais como quadro branco, pincel, livros e equipamentos eletrônicos (notebook, data show, caixa de som e máquina fotográfica) como forma de difusão e de registro das nossas atividades. Quanto à exposição dos conteúdos, consideramos que as discussões sobre os temas propostos em cada aula foram mediadas pelos professores responsáveis. Com efeito, cada professor sugeriu um tema, uma ementa, o(s) objetivo(s), a metodologia, a(s) forma(s) de avaliação e uma bibliografia básica.

Como resultados dessas atividades, alguns discentes desenvolveram ou estão desenvolvendo trabalhos de conclusão de curso sobre temas que estiveram diretamente relacionados aos módulos ministrados na extensão. Dentre eles, podemos destacar as seguintes pesquisas: impactos socioambientais causados pelo uso de agrotóxicos em plantações de abacaxi no 
município de Itapororoca/PB; mobilização política e sindical dos trabalhadores canavieiros do Brejo paraibano na década de 1980; migrações rurais-urbanas no contexto do município de Pilões/PB; impactos ambientais provocados pelo crescimento urbano sobre as áreas drenadas pelo Rio Cuiá (João Pessoa/PB); aspectos da religiosidade popular na Diocese de Guarabira/PB; a cidade de Guarabira/PB como polo de atividades terciárias na década de 2000; conflitos sociais e questões sindicais no Vale do Rio Mamanguape; práticas docentes nas escolas públicas de Guarabira/ PB; e por fim, a justiça trabalhista e o movimento sindical em Guarabira/ PB (década de 1980). Ademais, buscamos frisar que um dos extensionistas foi aprovado em um programa de pós-graduação (mestrado) na área de Agronomia.

\section{Considerações finais}

O nosso trabalho teve como escopo a possibilidade de um exercício pedagógico distanciado do monismo teórico relacionado à análise do espaço, razão pela qual privilegiamos a ampliação dos participantes a partir de diversas possibilidades científicas. Essa modalidade de problematização do espaço reverberou entre os inscritos (estudantes e egressos de História, Geografia, Letras e Direito) reflexões críticas sobre os grupos sociais, as relações sociais assimétricas, os conflitos sociais e as identidades nacionais e políticas.

Ao longo de um ano de trabalhos extensionistas, foram realizadas atividades na universidade e no plenário da Câmara Municipal da cidade de Guarabira/PB, sobretudo com relação às discussões sobre a diversidade de olhares a respeito da noção de espaço social, como algo produzido coletivamente e fruto de interações/tensões entre grupos/classes sociais em um dado tempo histórico. Como forma de ampliar a visão dos extensionistas, realizamos atividades pedagógicas com filmes e documentários (nacionais e estrangeiros), bem como fizemos trabalhos de campo nas cercanias da cidade de Recife (PE) sobre a ocupação espacial em uma metrópole regional nordestina, que desde a fase da América portuguesa foi foco de uma atividade exploratória com danos ao ambiente (derrubada da Mata Atlântica) e conflitos sociais, que mobilizaram as forças conservadoras no sentido de conter as rebeliões escravas, cujo espectro se manifestou ainda no século XIX. Além disso, um espaço social em que, no século XX, ocorreu a eclosão de um importante movimento social, as Ligas Camponesas, que denunciaram a nível internacional as relações sociais anacrônicas responsáveis pela pobreza rural decorrente de um modelo econômico capaz de associar o arcaico (o cambão) e o moderno (a usina) no seu cerne. Ademais, visualizamos como, em Pernambuco, a instalação da SUDENE (Superintendência de Desenvolvimento do Nordeste) estabeleceu um triângulo de desenvolvimento regional em estados como a Bahia, 
o Ceará e Pernambuco. E, por fim, junto aos extensionistas, fizemos uma visitação ao Instituto Ricardo Brennant, onde visualizamos o esforço colecionista do empresário, por meio da exposição de uma diversidade de exemplares da cultura material europeia e asiática, em uma instituição educativa edificada em formato de um castelo, em pleno Nordeste brasileiro. Todo nosso esforço teve por meta reflexões sobre a riqueza analítica, que pode ser dirigida a um determinado espaço, considerando os reflexos de fatores externos, cujo efeito pode ser a formação de enclaves econômicos, políticos ou culturais.

Essa experiência permitiu-nos a possibilidade de projetar um programa de extensão, a partir de temas tangenciais, abordados no projeto "Espaço social: visões e revisões". Além disso, as discussões realizadas suscitaram, entre vários participantes, o envolvimento com as temáticas e os referenciais teóricos, repercutindo no desenvolvimento de projetos de trabalhos de conclusão de curso, artigos e projetos para pós-graduações, sobretudo em História e Geografia.

\section{Referências Bibliográficas}

ARAÚJO, P.C. Eu não sou cachorro, não: música popular cafona e ditadura militar. Rio de Janeiro: Record, 2005.

BALANDIER, G. O poder em cena. Brasília: Universitária/UNB, 1982.

BALAKRISHNAN, G. (org.). Um mapa da questão nacional. São Paulo: Contraponto, 2000.

BOURDIEU, P. Coisas ditas. São Paulo: Brasiliense, 1990.

. O poder simbólico. Rio de Janeiro: Bertand Brasil, 1998.

. Razões práticas. Sobre a teoria da ação. Campinas: Papirus, 1996.

CARLOS, A.F.A. A cidade. São Paulo: Contexto, 1996.

CASTELLS, M. O poder da identidade. 5.ed. São Paulo: Paz e Terra, 2006 (v.2).

A sociedade em rede. A era da informação: economia, sociedade e cultura. São Paulo: Paz e Terra, 2009 (v.1).

COSTA, W.M. Geografia política e geopolítica. São Paulo: Universitária/USP, 2008. 
NEVES, F.C. Economia moral versus moral econômica (ou: o que é economicamente correto para os pobres?). Projeto História, São Paulo, 16, fev. 1998.

NEZ, E.; SIEBIGER, R.H. Apontamentos sobre vieses alienantes nos versos da música popular brasileira. Revista Acta Scietiarun Education. v. 33, n. 1, jan-jun 2011. Disponível em <http://periodicos.uem.br/ ojs/index.php/ActaSciEduc/article/view/11228>

FERNANDES, B.M. A formação do MST no Brasil. Petrópolis: Vozes, 2000.

FELICIANO, C.A. Movimento camponês rebelde. A reforma agrária no Brasil. São Paulo: Contexto, 2006.

GOHN, M.G. Teorias dos movimentos sociais. São Paulo: Loyola, 2007.

HOBSBAWM, E. Nações e nacionalismos desde 1780: programa, mito e realidade. Rio de Janeiro: Paz e Terra, 1990.

. A Era dos extremos - o breve século XX (1914-1991). 2.ed. São Paulo: Companhia das Letras, 2008.

POLLAK, M. Memória, esquecimento, silêncio.Estudos Históricos. Rio de Janeiro: Fundação Getúlio Vargas, v.2, n.3, 1989.

RODRIGUES, A.M. Moradia nas cidades brasileiras. São Paulo: Contexto, 2003.

. Estatuto da Cidade: função social da cidade e da Propriedade. Alguns aspectos sobre população urbana e espaço. Cadernos Metrópole. n.12, $2^{\circ}$ sem. 2004.

SANTOS, M. Técnica, espaço, tempo: globalização e meio técnico-científico-informacional. São Paulo: Hucitec, 1994.

. Por uma outra globalização. Rio de Janeiro: Record, 1999.

SANTOS, M.; SILVEIRA, M.L. O Brasil: território e sociedade no início do século XXI. Rio de Janeiro: Record, 2006.

SCOTT, J. Los dominados y el arte de la resistência. México: Era, 2000.

THOMPSON, E.P. Costumes em comum. São Paulo: Companhia das Letras, 1998. 